\title{
Skin gangrene as an extraintestinal manifestation of inflammatory bowel disease*
}

\author{
Yumi Cristina Komatsu ${ }^{1}$ \\ Maria Fernanda Feitosa de Camargo Boin ${ }^{1}$ \\ Thaís Helena Proença de Freitas ${ }^{1}$
}

\author{
Gabriela Cunha Capareli \\ Rute Lellis ${ }^{1}$ \\ Karine Simone ${ }^{1}$
}

\begin{abstract}
Inflammatory bowel diseases can commonly present many cutaneous lesions which can contribute to the diagnosis of the disease or its activity. The most frequent cutaneous or mucocutaneous manifestations suggesting ulcerative rectocolitis activity are erythema nodosum (3-10\%), pyoderma gangrenosum (5-12\%) and aphthous stomatitis $(4 \%)$. Other reactive skin manifestations related to immunological mechanisms associated with the inflammatory bowel disease are: Sweet's syndrome, arthritis-dermatitis syndrome associated with inflammatory bowel disease and leukocytoclastic vasculitis. We describe the case of a young man with diagnosis of ulcerative rectocolitis, which presented an extensive cutaneous gangrene secondary to microvascular thrombosis. The case represents a dermatologic rarity and should be recognized as a cutaneous manifestation related to the hypercoagulability state observed in the disease's activity.
\end{abstract}

Keywords: Gangrene; Infarction; Inflammatory bowel diseases; Necrosis; Skin abnormalities

\section{INTRODUCTION}

Several cutaneous manifestations are described in Inflammatory Bowel Disease (IBD), which were classified according to their etiopathogeny: 1) specific or granulomatous cutaneous diseases, whose histopathology is identical to the basic IBD, such as aphthous stomatitis, perineal fistulas, subcutaneous nodules; 2) reactive cutaneous manifestations with immunological mechanisms related to the basic disease activity, among which we highlight erythema nodosum, pyoderma gangrenosum, Sweet's syndrome, arthritisdermatitis syndrome associated with inflammatory bowel disease, vasculitides; 3 ) cutaneous dermatoses associated with IBD, such as psoriasis, secondary amyloidosis, vitiligo, acquired epidermolysis bullosa, which are rare; and 4) cutaneous manifestations secondary to complications from IBDs or adverse effects from treatment for IBDs, such as alterations associated with anemia by iron deficiency, and acrodermatitis enteropathica secondary to zinc deficiency. ${ }^{1}$ Crohn's disease and ulcerative rectocolitis encompass $90 \%$ of IBDs, with global incidence of 5 to 10 cases per 100,000 inhabitants/year. Ulcerative rectocolitis (URC) is three times more frequent than Crohn's disease and has greater incidence of cutaneous manifestations (34\%) and of thromboembolic phenomena like extra-intestinal manifestations. ${ }^{2}$

\section{CASE REPORT}

29-year-old man, of mixed race, with a history of ulcerative rectocolitis, had used only sulfasalazine for 3 years, with a history of onset of 2 erythematous areas on the left flank, measuring about $7 \mathrm{~cm}$, with well-defined limits, initially painful, which had evolved to fast-progression necrosis 5 days before (Figure 1). One of the lesions presented a peripheral blister (Figure 2). The left breast presented a painful tumor with hardened consistency for 1 month. He appeared to be in good general condition, afebrile and with no complaint of abdominal pains. The laboratory tests demonstrated normocytic normochromic anemia, discreet thrombocytosis $\left(467,000\right.$ platelets $\left./ \mathrm{mm}^{3}\right)$, ESR $62 \mathrm{~mm} / 1$ st hour and CRP $4.3 \mathrm{mg} / \mathrm{dl}$, abnormal liver function (SGOT $83 \mathrm{U} / \mathrm{L}$, ALT $91 \mathrm{U} / \mathrm{L}$, albumin $2.8 \mathrm{~g} / 100 \mathrm{ml})$, very high canalicular enzymes $(\mathrm{FA}=1079 \mathrm{U} / \mathrm{L}, \mathrm{GGT}=665 \mathrm{U} / \mathrm{L})$ and urine 1 with mild proteinuria $(0.25 \mathrm{mg}$ protein/ml). The research of cryoglobulins and immu-

\footnotetext{
Received on 23.07.2013.

Approved by the Advisory Board and accepted for publication on 16.10.2013.

* Work performed at Irmandade da Santa Casa de Misericórdia de São Paulo - Hospital Central - São Paulo (SP), Brazil.

Financial Support: none

Conflict of Interests: none

Santa Casa de Misericórdia de São Paulo - São Paulo (SP), Brazil.

(C)2014 by Anais Brasileiros de Dermatologia
} 
ne complexes (ELISA) was negative. Platelet function and prothrombin time were normal. He underwent biopsy of the edge of the skin lesion from which histopathological examination revealed microvascular thrombosis without signs of vasculitis (Figure 3).

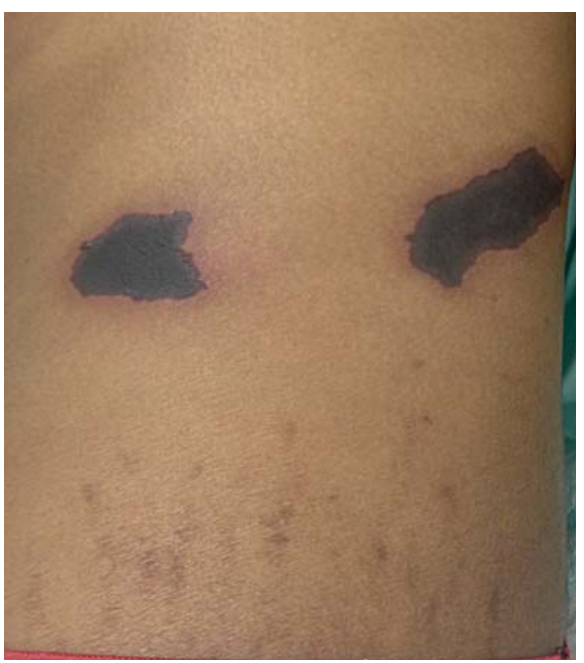

Figure 1:

Ulcers with necrotic surface, well-defined and angled limits and erythematous halo

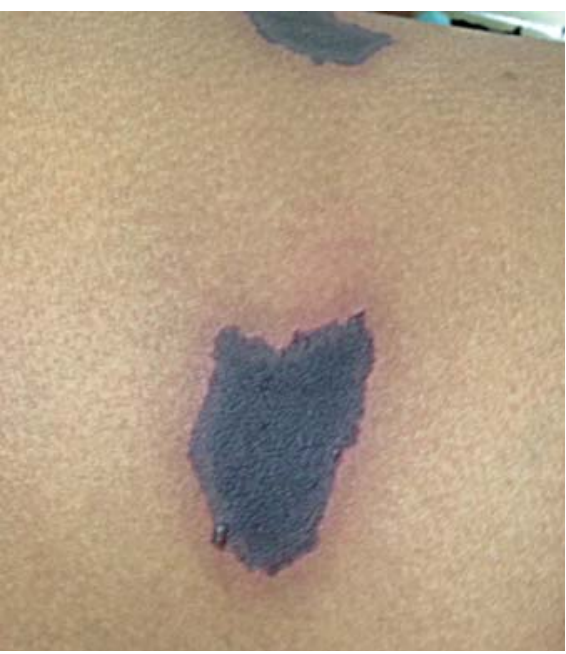

FIgURE 2:

Blister in the periphery of $\mathrm{cutaneous}$ lesion

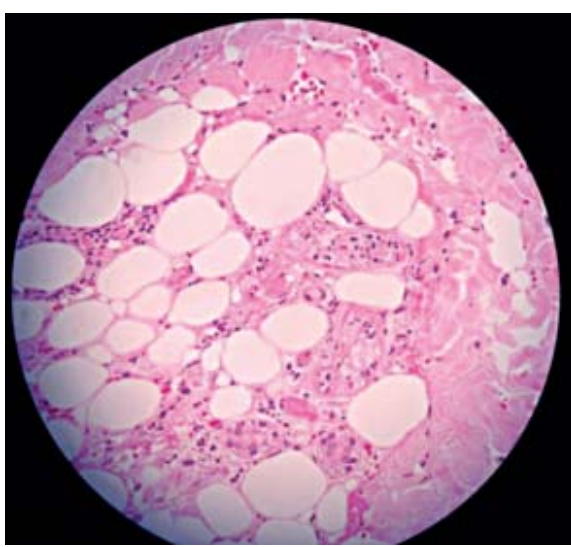

FIGURE 3

Microvascular thrombosis, without signs of vasculitis
Mammography of the left breast showed focal asymmetry in the retroareolar region, which anatomopathological examination revealed only glandular breast tissue without changes (Figure 4). Under the conditions presented, the diagnostic hypothesis for cutaneous gangrene associated with possible mastitis was made. The treatment of this patient included prednisone (1 $\mathrm{mg} / \mathrm{kg} /$ day) and sulfasalazine, with good evolution and progressive improvement of skin lesion.

\section{DISCUSSION}

Cutaneous manifestations occur in up to $50 \%$ of inflammatory bowel disease (IBD) cases and are frequently associated with a significant increase of morbidity and mortality, making it necessary to make therapeutic adjustments. Several cutaneous clinical pictures were described in IBD. In ulcerative rectocolitis (URC), the biggest incident is pyoderma gangrenosum, whereas in Crohn's disease it is erythema nodosum. ${ }^{1}$ Other lesions described are: psoriasis, erythema multiforme and hyperkeratosis, vitiligo, urticaria, pelagra and vesicular lesions. In the case described, we did not attribute the skin lesion to a proper vasculitis, but to microvascular thrombosis, an uncommon complication of IBD - URC. It arises from the hyper-

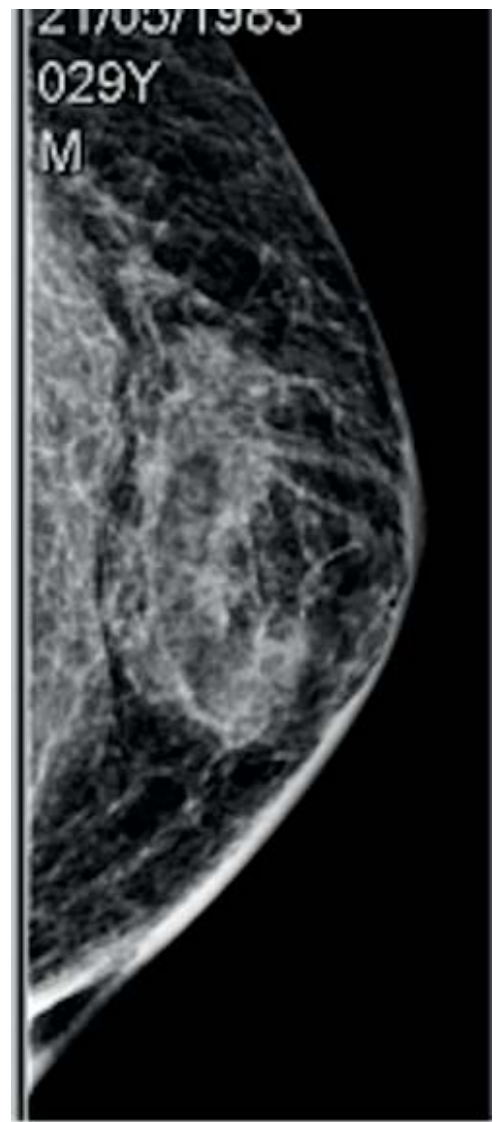

Figure 4:

Focal asymmetry in the retroareolar region of left breast 
coagulability present in the URC. ${ }^{3}$ The presence of mastitis can also be associated with the inflammatory disease by the same skin mechanism, however this was not proven in the specimen from the anatomopathological breast exam. Studies show that this state of hypercoagulability is associated with deep venous thrombosis in 5\% of cases, and there is increased risk of cerebral venous thrombosis. Such state of hypercoagulability can be the result of increased levels of coagulation factor V, VIII and fibrinogen, and to a decline in levels of antithrombin II due to loss of proteins by enteropathy, whereas circulating cryoglobulins are other potential causes of cutaneous gangrene. ${ }^{4}$ Furthermore, other studies showed that the increased platelet count in ulcerative rectocolitis is associated with thromboembolic disease, as found in this case. ${ }^{5}$ The cutaneous gangrene is characterized by a clinical picture of sudden onset of localized pain, erythema, followed by localized necrosis of epidermis, which may or may not happen concurrently with the intestinal inflammatory phase and with thrombotic phenomena in other sites. In this case, the patient was not in an active disease phase; however, the diagnosis was primary sclerosing cholangitis, an auto-immune disease also associated with rectocolitis. ${ }^{6}$ The management of extensive cutaneous gangrene can be done with prednisolone and intravenous heparin. Complications arising from the use of anticoagulants during colitis activity were not described. Nevertheless, one can choose to use low molecular weight heparin in cases of significant bleeding. In this case the cutaneous disease was self-limiting, so an anticoagulant was not needed for resolution of the clinical picture, only prednisone. Biopsy of the edge of the cutaneous lesion of this patient demonstrated microvascular thrombosis (anatomopathological diagnosis: thrombosing vasculopathy), with no evidence of vasculitis; the finding is compatible with the clinical picture of cutaneous gangrene.

It is important to suspect cutaneous gangrene when we face uncommon skin lesions that clinically do not suggest pyoderma gangrenosum, in a patient with rectocolitis. Complete hemogram and coagulogram must be performed and early anticoagulation with heparin must be considered, in order to prevent progression of cutaneous infarction. ${ }^{4}$

This case represents a dermatological rarity that demonstrates that the extra-intestinal manifestation of the cutaneous gangrene type must be recognized as another cutaneous manifestation related to the activity of the URC.

\section{REFERENCES}

1. Huang BL, Chandra S, Shih DQ. Skin manifestations of inflammatory bowel disease. Front Physiol. 2012;3:13.

2. Diógenes AHMD, Soares JTAS, Prokopowitsch AS, Neto EFB, Gonçalves CR, Neto ML. Doença Inflamatória Intestinal com Gangrena Cutânea Mimetizando a Poliarterite Nodosa. Rev Bras Reumatol. 2003;43:334-6.

3. Stapleton SR, Curley RK, Simpson WA. Cutaneous gangrene, secondary to focal thrombosis - important cutaneous manifestation of ulcerative colitis. Clin Exp Dermatol. 1989;14:387-9.

4. Singh S, Noshirwani K. An unusual cutaneous manifestation of ulcerative colitis: thrombotic skin gangrene. Postgrad Med J. 1996;72:623-4.

5. Webberley MJ, Hart MT, Melikian V. Thromboembolism in inflammatory bowel disease: role of platelets. Gut. 1993;34:247-51.

6. Lee YM, Kaplan MM. Primary sclerosing cholangitis. N Engl J Med. 1995;332:924-33.

\author{
MAILING ADDRESS: \\ Yumi Cristina Komatsu \\ Rua Dr Cesário Mota Junior, 112. \\ Vila Buarque \\ 01221-020 - São Paulo - SP \\ Brazil \\ E-mail: yumi.komatsu@hotmail.com
}

How to cite this article: Komatsu YC, Capareli GC, Boin MFFC, Lellis R, Freitas THP, Simone K. Skin gangrene as an extraintestinal manifestation of inflammatory bowel disease. An Bras Dermatol. 2014;89(6):967-9. 